\title{
ESTIMATIONS IN DISTRIBUTION AND GROWING CHARACTERISTICS OF WILD HYPERICUM PERFORATUM L. (HYPERICACEAE) POPULATIONS DURING THE LAST DECADE IN ARMENIA
}

\author{
Armine Abrahamyan \\ Armenian State Agrarian University, Horticultural Department \\ Yerevan, Teryan 74, 009 Armenia \\ Ph.: +(371) 25855196, e-mail: arm_abrahamyan@yahoo.com
}

\begin{abstract}
The small mountainous country of Armenia has a rich flora of ca. 3600 species of vascular plants, which makes about half of entire Caucasian flora, distributed across desert and semi-desert, steppe, forest and alpine landscape. Anthropogenic threats to this biodiversity such as overpopulation, deforestation and urbanization have simultaneously hindered research and increased the need for it. Of the ca. 500 species in the Armenian flora with a record of medicinal and/or economic use, ca. 50 species are used in the folk medicine and include both wild-collected (Crataegus sp., Hypericum perforatum, Artemisia absinthium) and cultivated (Chamomilla recutita, Mentha piperita, Crocus sativus) species (1). Only limited information on the genetic biodiversity, population location, structure and size, and conservation status of most of these species is, however, at this time available. During 2007-2009, field studies were conducted to re-locate populations of wild Hypericum perforatum L. (common St. Johnswort, Hypericaceae) on the basis of historical (i.e. herbarium voucher, (2)) records, and to discover new populations. The plants habitat and phenological characteristics were estimated growing in different populations. GPS map of population distribution was created and its overall sizes were assessed. According to historical records this species had been widely distributed in the south regions of Armenia, however almost half of the populations no longer existed in the cited locations. However, 2 new populations were loacated in the south east regions. Evidence that the abundance and distributional range of $H$. perforatum is expanding in the north region was collected. This research provided baseline data that can be used for the development of further ex situ and in vitro strategies to conserve unique genotypes of this important medicinal and culinary species in Armenia.
\end{abstract}

\section{Introduction}

The small mountainous country of Armenia has a rich flora of ca. 3600 species of vascular plants, which makes about half of entire Caucasian flora, distributed across desert and semidesert, steppe, forest and alpine landscape. According to International Conservation Armenia is one of the 34 active areas of the earth in respect with being the most dangerous and having rich biodiversity. Anthropogenic threats to this biodiversity such as overpopulation, deforestation and urbanization have simultaneously hindered research and increased the need for it. Of the ca. 500 species in the Armenian flora with a record of medicinal and/or economic use, ca. 50 species are used in the folk medicine and include both wild-collected (Crataegus sp., Hypericum perforatum, Artemisia absinthium) and cultivated (Chamomilla recutita, Mentha piperita, Crocus sativus) species [1].Only limited information on the genetic biodiversity, population location, structure and size, and conservation status of most of these species is, however, at this time available. This sudies became more significant in order to have relevan data for assessing the risk impact on global climate change of these valuable wild medicinal plants population's conservation status.

\section{Materials and methods}

The genus Hypericum 1. (St. John's wort) belong to Hypericaceae family. Includes at the most resent count 484 species that are either naturally occuring on, or which have been introduced to, every continent in the world except Antarctida. Hypericum perforatum (St. John's Wort;) is considered a noxious weed in many countries, but its medicinal use dates back to ancient 
Greece. It has a 2400 year history from ancient Greece. The name Hypericum is derived from Greek "hyper" meaning above and "eikon" meaning picture. This refers to a practice of placing flowers above religious images to keep away evil. In modern medicine, standardized Hypericum extracts are commonly used for treatment of mild depression and anxiety disorders, and in some countries (e.g. Germany) more so than synthetic antidepressant medication.In Armenia it grows only in a wild form and more then 7 species of Hypericum known in Armenia. Records about its cultivation no found here. It grows wild from 600 to 1800 elevations in Aragats, Igevan, Kotayk, Stepanavan and other regions. During 20072009, field studies were conducted to re-locate populations of wild Hypericum perforatum L. on the basis of historical (i.e. herbarium voucher) records, and to discover new populations. The selection of researching territories has been realized by taking into account the existing data and theoretically possible existence of new population. These territories vary with their geographical location, elevation, soil types, climatic conditions etc.

The growth, phenological and habitat characteristics of the plants, and overall population size were assessed. GPS maps of present and past population distribution were created. During the growing seasons we have realized many field trips almost all regions of Armenia.

For accounting population density we have applied a systemantic sampling method, where population density and number of samples could be large $(100<)$. Population density estimated according to traditional statistical methods, where population density $(\mathrm{N})$ standard deviation (S.D.), and standard error (S.E.), which is the standard deviation of the sample mean.

$$
\text { S.E. }=\frac{\text { S.D. }}{\sqrt{N}} \quad \text { or } \quad S_{x}=\frac{S_{X}}{\sqrt{N}}
$$

\section{Results and analysis}

According to the result of conducted field trips and expeditions, it has been estimated changes in distribution and abundance of $H$. perforatum L. Populations. The following map, which is created according with experimental data has shown current population distibution and structure of this plant.

\section{Distribution and Changes of Wild Hypericum perforatum L. Populations}

(in regard with implemented field trips in 2007-2009)

Although historical records indicated that this species had been widely distributed in the northern and south regions of Armenia, nearly half of the populations no longer existed in the south region. However, one of the new populations as it is obvious from the map is distributed in the south region of Armenia. Others are located in North and Central regions. Evidence that the abundance and distributional range of Hypericum Perforatum $L$ is expanding in North region was collected. It also, has trend to increase its distributional areas into central regions. Some anthropogenic threats that were identified as part of the study included poor land management (erosion, overgrazing), increasing population pressure (impact of livestock overpopulation, improper human development), and excessive or inappropriate collection for the purposes of local sale/usage (due to lack of knowledge/training of collectors).

Realized different multiple observations over the populations have exposed phenological and habitat characteristics of the plants as well as assessed population size, its abundance and the number of ripen plants. The following table 1 shows certain data in respect with them. 


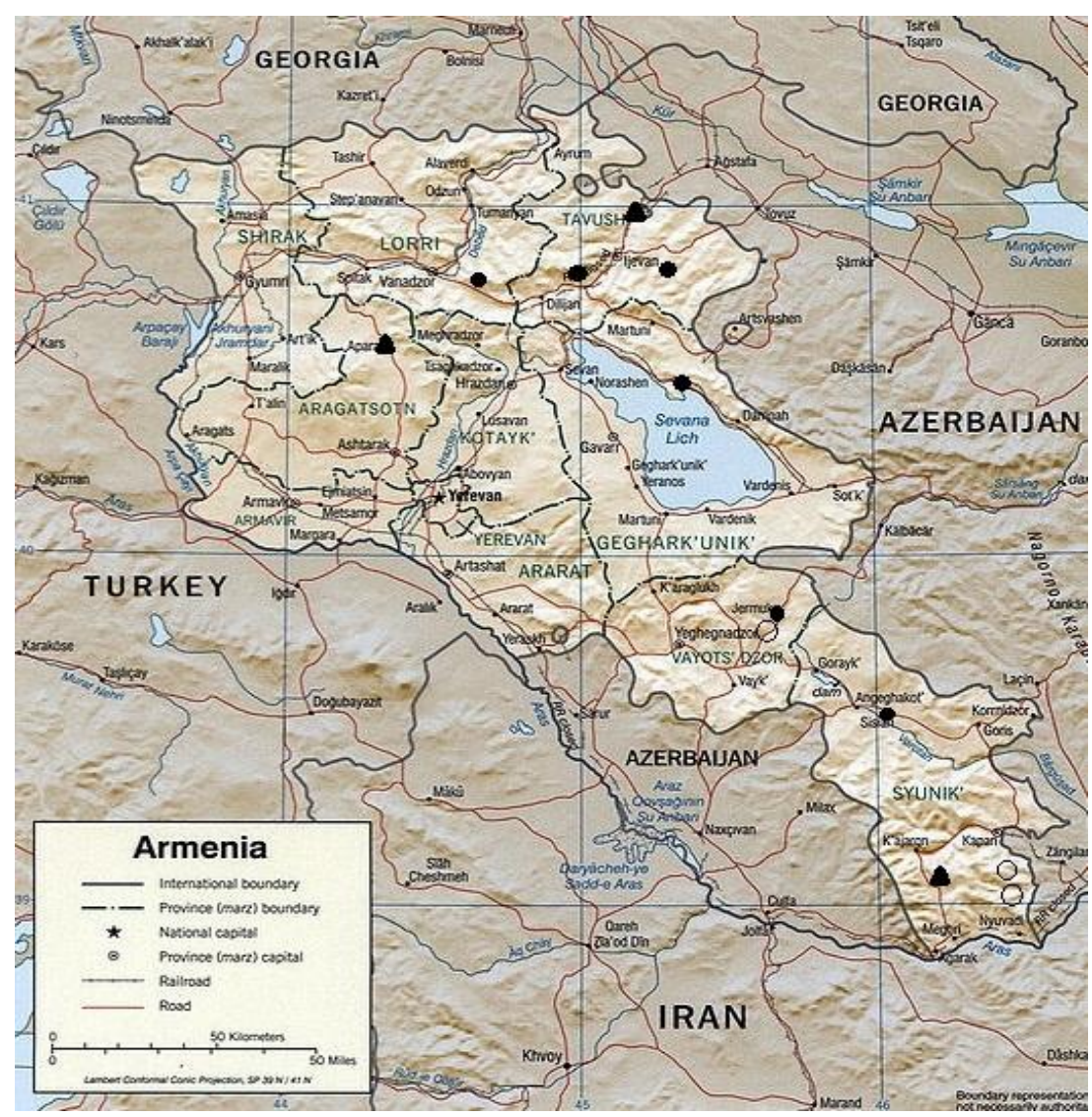

Fig. 1.

- New population

- Population re-located from historical records

○ Historical population not re-located (presumed extinct)

Table 1.

Populations' Sizes, Abundance, Plant Highness, Grow intensity (2007-2009 field trips)

\begin{tabular}{|l|l|c|c|c|c|c|}
\hline \multicolumn{2}{|c|}{ Ropulation } & \multirow{2}{*}{$\begin{array}{c}\text { Size, } \\
\boldsymbol{m}^{2}\end{array}$} & $\begin{array}{c}\text { Location, } \boldsymbol{m} \\
\text { (above sea } \\
\text { level })\end{array}$ & $\begin{array}{c}\text { Population } \\
\text { Density, } \\
\text { plant/1m }\end{array}$ & $\begin{array}{c}\text { Plant } \\
\text { highness, } \\
\text { cm }\end{array}$ & $\begin{array}{c}\text { Seedlings } \\
\text { quantity/1m }\end{array}$ \\
\hline \multirow{2}{*}{ Sjuniq } & $\underline{\text { Tjakaten }}$ & 400 & 1050 & 3 & $80-90$ & 2 \\
\cline { 2 - 7 } & Sisyan & 207 & 2099 & 2 & $15-20$ & 4 \\
\hline Vajoc Dzor & Jermuk & 226 & 2103 & 1 & $70-80$ & 1 \\
\hline \multirow{2}{*}{ Lori } & Stepanavan & 363 & 1400 & 4 & $65-70$ & 3 \\
\cline { 2 - 7 } & Margahovit & 305 & 1761 & 2 & 65 & 4 \\
\hline Aragatsotn & Aparan & 298 & 1885 & 3 & $25-30$ & 2 \\
\hline \multirow{2}{*}{ Tavush } & Idjevan & 427 & 730 & 3 & $75-85$ & 3 \\
\cline { 2 - 7 } & Dilijan & 449 & 1450 & 3 & $75-80$ & 3 \\
\hline Gerarkunik & Drakhtic & 170 & 1850 & 3 & $55-65$ & 2 \\
\hline
\end{tabular}

From 9 populations 4 are distributed in the Northen regions of the country and among them there is recorded a new Stepanavan population, $1400 \mathrm{~m}$ above sea level. According to table 1, the biggest populations with relatively high density are found in Northen part of the country (Idjevan, Dilijan, Margahovit). 
Although historical recors shows that $H$. Perforatum L. populations had been widely distributed in the south regions of Armenia, however almost half of the populations no longer existed in the cited locations (e.g. in 1956 it has been recorded a population in Herher area, which is no longer existed in the cited location ). Antropogenetic threaths in south regions have more negative influence on the conservation status of this species by comparision in Northen regions. On the other hand, a new population is recorded at Tjakaten (South Region) a new highway area from Kapan, in the South Part of the country. Distributed at $1050 \mathrm{~m}$ above sea level this population is demonstrated intensive growing capacity. Plant highness is the highest one and density is also a relatively high. Population in Jermuk, is identified as the old one (seedlings number very the lowest recorded in this population). The area of this population tends to decrease as the population wildy collected this plant for remedies.

\section{Conclusion and inference}

This research provided baseline data that can be used for the development of further ex situ and in vitro strategies to conserve unique genotypes, as well as to assess the sustainability of wild populations with regard to the IUCN Red Book Criteria, of this important medicinal and culinary species in Armenia.

\section{References}

1. Fayvush, G., Danielyan T., Nalbandyan A. (2004) Armenia as a producer of medicinal plants: possibilities and perspectives. Available online (accessed 12 April 2010): http://www.nature-ic.am/NCSA/Publication/ Medical_Plants_eng.pdf.

2. Takhtagyan A. L. "Flora of Armenia", part 5, Yerevan, 1966, p. 382 